\title{
Recovery of platinum from secondary materials: electrochemical reactor for platinum deposition from aqueous iodide solutions
}

\author{
R. J. Dawson ${ }^{1,2}$ - G. H. Kelsall ${ }^{1}$
}

Received: 13 May 2016/Accepted: 23 September 2016/Published online: 29 September 2016

(c) The Author(s) 2016. This article is published with open access at Springerlink.com

\begin{abstract}
A circulating bed particulate reactor was designed, developed, and demonstrated to facilitate recovery of dilute dissolved platinum species from concentrated aqueous iodide solutions, an essential component for the overall process proposed for the recovery of Pt from secondary materials using benign conditions. A detailed design for the reactor was undertaken using the Fluent ${ }^{\mathrm{TM}}$ computational fluid dynamics software to predict electrolyte and particulate flows, and Maple ${ }^{\mathrm{TM}}$ for simulating the electrochemical performance. Insight was gained into the design features required for successful operation and demonstrated in the reactor design, including effects of electrolyte flow rate, additional inlet nozzle locations, bed depth in the direction of current flow, draft tube width, and its proximity to the inlet nozzle. Good agreement was found between the reactor model predictions and the results of the experimental matrix conducted to define the reactor performance. The electrodeposit produced by the reactor was found to be adherent even under transport controlled operation, supporting the assertion that mechanical interactions in a circulating particulate bed can improve deposit morphologies in transport and mixed controlled deposition regimes. The model predictions and the experimental results both showed that the reactor could be operated with charge yields of ca. $45 \%$, corresponding to specific electrical energy consumptions of ca. $1.0 \mathrm{kWh} \mathrm{kg}^{-1} \mathrm{Pt}$ and
\end{abstract}

R. J. Dawson

r.dawson@lancaster.ac.uk

1 Department of Chemical Engineering, Imperial College London, London SW7 2AZ, UK

2 Present Address: Engineering Department, Lancaster University, Lancaster LA1 4YR, UK hence negligible operating cost compared with the value of the product.

\section{Graphical abstract}

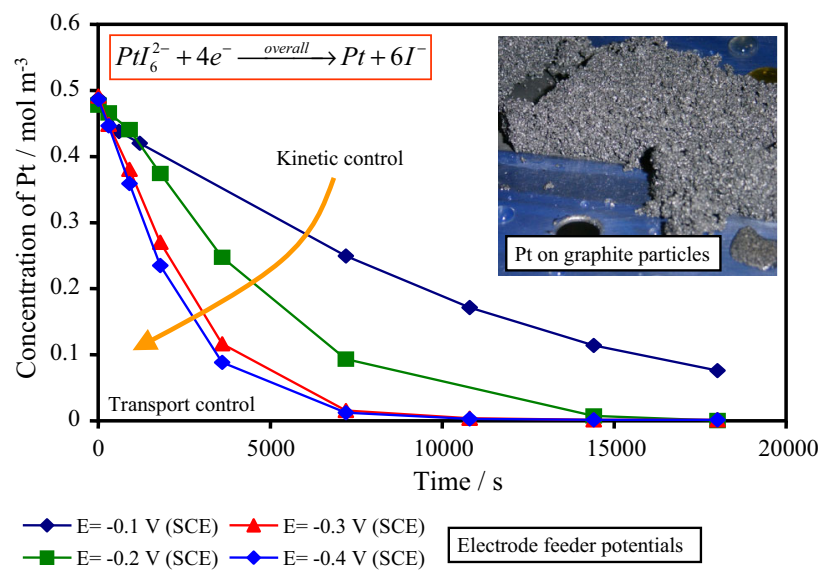

Keywords Iodide - Platinum - Circulating particulate bed electrode $\cdot$ Tri-iodide $\cdot$ Secondary materials
Abbreviations
$A_{\mathrm{s}} \quad$ Specific surface area $\left(\mathrm{m}^{-1}\right)$
$A_{\mathrm{f}} \quad$ Area of feeding electrode $\left(\mathrm{m}^{-2}\right)$
$d_{\mathrm{p}} \quad$ Particle diameter $(\mathrm{m})$
$D_{i} \quad$ Diffusion coefficient for species $i$ in solution $\left(\mathrm{m}^{2}\right.$ $\left.\mathrm{s}^{-1}\right)$
E Electrode potential versus SCE reference electrode (V)
$E_{\mathrm{L}} \quad$ Height of reactor (approximation for spouted bed) (m)
$I_{\mathrm{e}} \quad$ Current flowing in solid electrolyte (A)
$I_{\mathrm{S}} \quad$ Current flowing in pore electrolyte (A)
$j_{0} \quad$ Exchange current density $\left(\mathrm{A} \mathrm{m}^{-2}\right)$ 
$j_{\mathrm{f}} \quad$ Total faradaic current (A)

$k_{\mathrm{m}} \quad$ Mass transport rate coefficient $\left(\mathrm{m} \mathrm{s}^{-1}\right)$

$L_{\mathrm{Y}} \quad$ Height of particulate bed (approximation for spouted bed) (m)

$u \quad$ Fluid velocity $\left(\mathrm{m} \mathrm{s}^{-1}\right)$

$w_{\mathrm{Pt}}^{\mathrm{e}} \quad$ Specific electrical energy consumption for $\mathrm{Pt}$ deposition $\left(\mathrm{kWh} \mathrm{kg}^{-1} \mathrm{Pt}\right)$

$X \quad$ Depth into porous electrode for Newman-Tobias model (m)

a Transfer coefficient (1)

$\phi_{\mathrm{e}} \quad$ Solid electrode potential (V)

$\phi_{\mathrm{s}} \quad$ Pore electrolyte potential (V)

$\Phi_{\mathrm{Pt}}^{\mathrm{e}} \quad$ Cathode charge yield for Pt deposition (1)

$v_{\mathrm{e}} \quad$ Electron stoichiometry (1)

$Q_{\text {exp }} \quad$ Total charge passed (C)

$Q_{\mathrm{th}} \quad$ Theoretical charge required for reaction (C)

$V \quad$ Electrolyte volume $\left(\mathrm{m}^{3}\right)$

$\mu \quad$ Dynamic viscosity $\left(\mathrm{kg} \mathrm{s}^{-1} \mathrm{~m}^{-1}\right)$

$\rho_{\mathrm{S}} \quad$ Solids density $\left(\mathrm{kg} \mathrm{m}^{-3}\right)$

$\rho_{\mathrm{L}} \quad$ Liquid density $\left(\mathrm{kg} \mathrm{m}^{-3}\right)$

$\sigma_{\mathrm{e}} \quad$ Effective solid electrode conductivity $\left(\mathrm{S} \mathrm{m}^{-1}\right)$

$\sigma_{\mathrm{s}} \quad$ Effective pore electrolyte conductivity $\left(\mathrm{S} \mathrm{m}^{-1}\right)$

$v \quad$ Kinematic viscosity $\left(\mathrm{m}^{2} \mathrm{~s}^{-1}\right)$

Sh $\quad$ Sherwood number $=\frac{k_{\mathrm{m}} d_{\mathrm{p}}}{D_{i}}(1)$

Sc $\quad$ Schmidt number $=\frac{D}{D_{i}}(1)$

Re Reynolds number $=\frac{u d_{\mathrm{p}} \rho_{\mathrm{L}}}{\mu}(1)$

Ga Galileo number $=\frac{\rho_{L}^{2} d_{p}^{3} g}{\mu^{2}}(1)$

Mv Density number $=\frac{\rho_{\mathrm{S}}-\rho_{\mathrm{L}}}{\rho_{\mathrm{L}}}(1)$

F Faraday constant, $96485.34\left(\mathrm{C} \mathrm{mol}^{-1}\right)$

PGM Platinum group metal (1)

DSA Dimensionally stable anode (1)

SCE Saturated $(\mathrm{KCl})$ calomel electrode $(+0.245 \mathrm{~V}$ vs. SHE) (1)

SHE Standard hydrogen electrode (1)

\section{Introduction}

In the previous publications [1, 2], we proposed an aqueous electrochemical process for the recovery of platinum and other precious metals from secondary materials, such as spent automobile exhaust catalyst, waste electrical and electronic equipment (WEEE), and end-of-life fuel cells. In principle, this obviates the need for extremely acidic and aggressive conditions used by the previous authors [3-8] investigating such hydrometallurgical processes. We demonstrated that the tri-iodide oxidant of the tri-iodideiodide couple is a feasible chemical system for both the dissolution from the waste material and recovery stages by electrodeposition $[2,9,10]$. Recently, we have shown that high recoveries are achievable from end-of-life polymer electrolyte fuel cells (PEMFC) in acceptable timescales [9]. A critical part of the proposed process is an energyefficient electrochemical reactor for the tri-iodide (re-) generation and platinum electrodeposition. This was best achieved with a membrane-divided electrochemical reactor, at the cathode of which the dissolved metal was deposited, whilst the tri-iodide was re-generated simultaneously at the anode.

To achieve an acceptably small volume and hence low capital cost of the electrochemical reactor, the cathode must have a high specific surface area, since the concentrations of metal ions from a leach reactor are likely to be low (ca. $1 \mathrm{~mol} \mathrm{~m}^{-3}$ ); otherwise, the volumetric productivity would be unacceptably low. Keeping the platinum concentrations low in solution also maximises the thermodynamic driving force for dissolution and avoids problems of limited solubility of platinum oxidation product, both of which are advantageous. A high surface area cathode can be achieved in various designs, but a cathode in the form of a circulating particulate bed is particularly attractive for the following reasons:

- High mass transport rates, especially important for electrodeposition from solutions with low reactant concentrations.

- High electrical conductivity through the bed, for more uniform spatial distributions of electrical potential and reaction rates and to decrease the probability of bipolarity of particles and re-dissolution of metal.

- Particles in constant motion obviate the problem of deposits bridging between adjacent particles, and their mechanical interactions may improve deposit morphologies.

- Designs can incorporate the facility for particles to be harvested and re-inserted continually, using hydraulic transport in and out of the bed.

A circulating particulate bed can have various embodiments, but all have a region of high particle velocity upwards and regions of descending packed beds of particles in which the bulk of the reaction occurs. The use of circulating particulate beds (which can also be referred to as spouted beds) for metal electrowinning, particularly copper and zinc, has been reported by various authors [11-15]. These authors have investigated both the hydrodynamic performance and the electrochemical performance, demonstrating that good deposit quality can be achieved in an efficient continuous process.

Here, we report the results of the design and development of the circulating particulate bed cathode and complete electrochemical reactor to be used in the proposed platinum recovery process. 


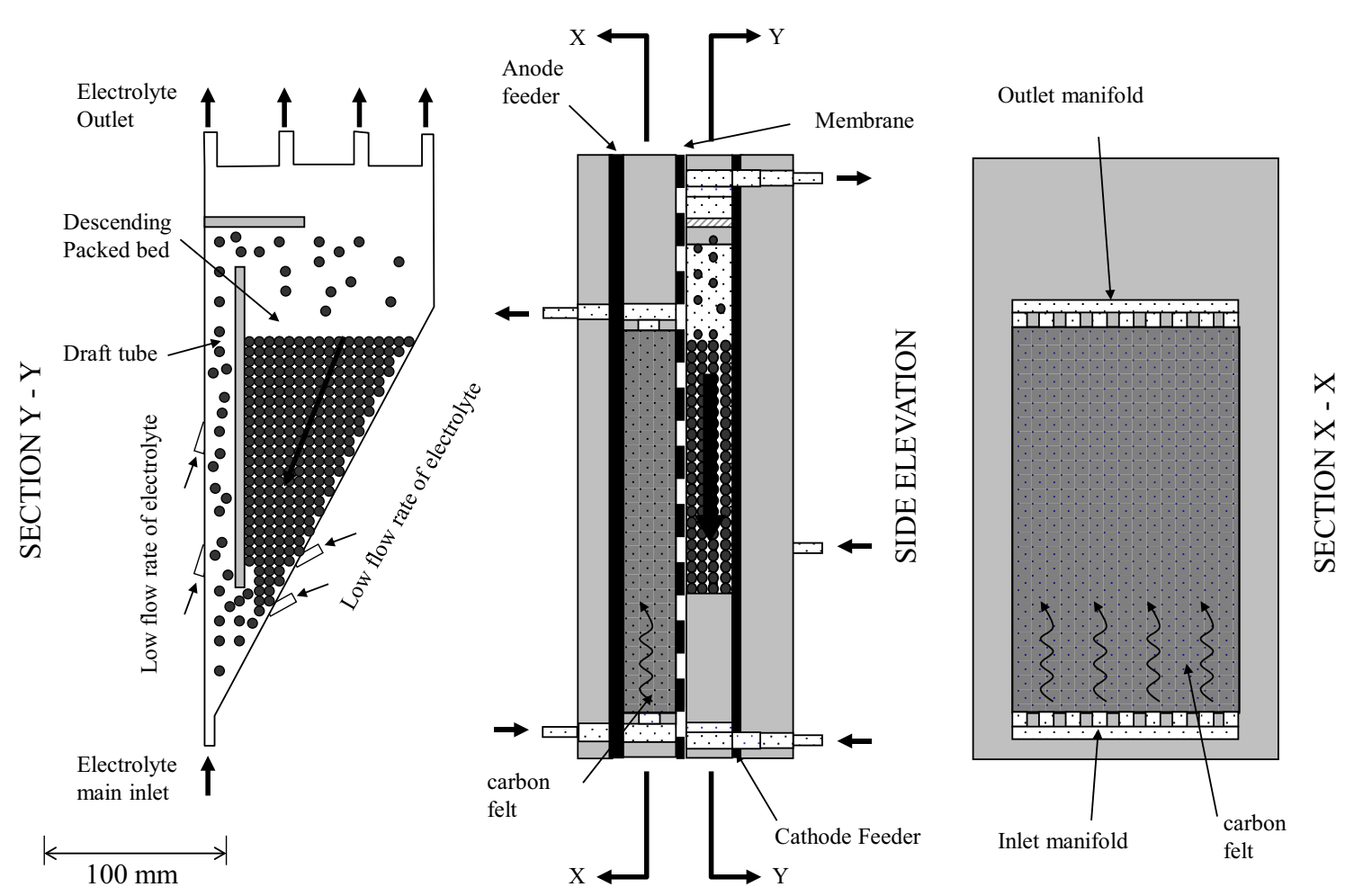

Fig. 1 Side elevation of revised reactor design with sections showing the descending packed bed cathode arrangement and carbon felt anode

\section{Experimental}

\subsection{Preparation of solutions}

All solutions were made using analytical or ACS (American Chemical Society) reagent grade chemicals. The water was purified first by reverse osmosis (Elga Elgastat Prima), then by deionisation (Elga Elgastat Maxima), giving a resistivity of $1 \times 10^{6} \Omega \mathrm{m}$. Solutions were deoxygenated using 'oxygen-free' nitrogen (BOC 'zero grade' $\mathrm{N}_{2}$ or from a Domnick Hunter NG104 nitrogen generator).

\subsection{Equipment}

Electrochemical measurements were made with Autolab Model PGstat 30 (with $10 \mathrm{~A}$ current booster when required) potentiostat/galvanostat (Eco Chemie B.V, The Netherlands) controlled by a computer. Most measurements of the concentration of the platinum iodo species were made using a Hewlett Packard (Agilent Technologies UK Limited, Stockport, UK) HP 8452A UV-Vis spectrophotometer after conversion of the dissolved platinum to the $\mathrm{Pt}^{\mathrm{II}}$ form using small amounts of ascorbic acid [16]. When platinum levels were present below $2 \times 10^{-6}$. mol dm ${ }^{-3}$, an Optima 2000DV (Perkin Elmer, Wellesley,
MA, USA) inductively coupled plasma optical emission spectrometer (ICP-OES) was used to determine the concentrations accurately.

A National Instruments USB6009 data acquisition module was used in conjunction with the LabView software to monitor reactor potential differences and electrolyte flow rates. During the development of the kinetic model, the deposition of platinum from the concentrated iodide solutions was studied using a rotating disc electrode (RDE) system (Pine Instrument Company, Grove City, PA, USA), with a vitreous carbon disc (model MT28). These electrodes were prepared by the conventional polishing using $0.3 \mu \mathrm{m}$ alumina particles in ultra-pure water and subsequently sonicated in water. Platinum flag electrodes were used as counter electrodes for these voltammetric experiments and were made from high purity $\mathrm{Pt}$ spot welded to high purity $\mathrm{Pt}$ wire (Goodfellow Ltd., Cambridge, UK).

\subsection{Circulating particulate bed cathode}

A diagram of the prototype design is shown as a front elevation in Fig. 1.

After some preliminary studies with the early reactor designs, some particular design features were developed to enhance performances, as summarised below: 
- Reactor depth in direction of current flow should be no more than around $10 \mathrm{~mm}$ to achieve an acceptably narrow range of electrode potentials in the bed and to minimise the risk of hydrogen evolution.

- Main inlet designed as a slot the full depth of the electrode with no horizontal surfaces.

- Extra electrolyte introduced though slots along angled side to the descending packed bed to improve bed descending velocity and to remove dead spots of no particle movement.

- Extra electrolyte introduced at base of draft tube and halfway up though slots to improve draft tube flow.

- Multiple outlets to reduce the outlet velocity.

In the reactor, the distribution of fluid and hence particle flow was complex, with many factors affecting the behaviour. Analytical models have been proposed for circulating particulate beds [17-19] as electrodes and also as dryers. However, the models proposed would be difficult to adapt to the specific complex geometries and flows involved and could not be used to predict the troublesome behaviour experienced at abrupt changes of geometry. computational fluid dynamics (CFD) software (Fluent ${ }^{\mathrm{TM}}$ ) has been used to model both the flow of fluid and the flow of solid phase successfully in spouted bed driers [20,21]. Therefore, Fluent ${ }^{\mathrm{TM}}$ was used to investigate the flow in the reactor, using a two-phase Eulerian model in which the behaviour of the particulate material and interaction with the electrolyte can be simulated effectively. This allowed the likely granular volume fraction in the descending packed bed to be determined, together with the likely range of suitable electrolyte flow velocities to produce effective circulation.

The cathode feeder was made from (SAE) 430 grade stainless steel. A cation-permeable membrane (Nafion 425, DuPont Inc., DE, USA) was used to separate anolyte and catholyte, preventing large anionic metal complexes and iodide/tri-iodide anions from transferring between compartments. This precluded an effective chemical short circuit from increasing electrical energy consumptions. A small $0.5 \mathrm{~mm}$ hole was made in the feeder above the height of the bed with an ' $\mathrm{O}$ ' ring seal to a probe that would sense the solution potential at the feeder electrode/electrolyte interface, enabling reliable potential control of the feeder electrode.

\subsection{Preparation of bed substrate material}

There were some important requirements and operation for platinum electrowinning using the circulating particulate bed electrode:

- The leach solutions used to dissolve Pt in neutral conditions were $4 \mathrm{M}$ (potassium) iodide [2] and the density of which was ca. $1.42 \mathrm{~g} \mathrm{~cm}^{-3}$, similar to that of possible particulate materials, such as carbon.

- Due to the value of the platinum, seeding the particles to nucleate deposit had to be conducted very carefully. High overpotentials required to nucleate platinum on a foreign substrate necessitate a seeding process [2], without which an uneven coating of deposit and inefficient initial operation would have resulted.

Dense inert substrates were sought; possible solutions considered were: tin shot, lead shot, silvered-glass ballotini beads, vitreous carbon, and graphite. The cost, chemical stability, and flow properties of tin and lead precluded their use, so more intensive investigations focused on silveredglass beads, vitreous carbon, and graphite. Insufficient density difference between the available vitreous carbon beads and the electrolyte precluded their use, whilst the dominance of silver dissolution/deposition reaction prevented the successful adoption of silver-coated glass beads.

Graphite had been considered early in the search for a suitable substrate, since it is both dense $\left(2.25 \mathrm{~g} \mathrm{~cm}^{-3}\right)$ and its electrically conductive is more than twice that of vitreous carbon. Therefore, $180-850 \mu \mathrm{m}$-sized graphite chips (20-80 mesh graphite chips from Alfa Aesar, Heysham UK, product code 10131) were obtained, and the largest size fraction, $600-850 \mu \mathrm{m}$, was separated for use by sieving to improve the hydrodynamic behaviour of the bed. Although stated as having an average density of $2 \mathrm{~g} \mathrm{~cm}^{-3}$, the apparent density of the chips was variable due to porosity in the graphite, so only the most dense fraction was separated for use in the reactor. This was achieved using them in a tubular circulating bed reactor in $4 \mathrm{M} \mathrm{KI}$ for several hours, resulting in the less dense fraction being transported out of the bed and being discarded. The chips used were of a low specific surface area, such that the geometric area of the chips was considered to be the effectively useful area. The surface area of the bed was then estimated for the mean size by the weight of a known volume of particles, assuming the density to be the average quoted for the material.

To improve the effective conductivity of the bed and the kinetics of metal electrodeposition, a seeding process was conducted. A solution of $9.5 \mathrm{~mol} \mathrm{~m}^{-3} \mathrm{PtI}_{6}{ }^{2-}$ in $4 \mathrm{M} \mathrm{KI}$ was made from chloroplatinic acid phosphate buffered to $\mathrm{pH}$ 5.8. A series of potential pulses of $-0.45 \mathrm{~V}$ (SCE) were applied over $30 \mathrm{~s}$ time frames, with the bed not moving, using the full output current from the Autolab PGSTAT 30 with 10 A current booster. In between pulses, the bed was circulated to allow the particles to change positions, enabling $\mathrm{Pt}$ to nucleate on all the particles, allowing them to grow uniformly. Electrodeposition at a constant (feeder) potential of $-0.25 \mathrm{~V}$ (SCE) was then carried out for $5 \mathrm{~h} 40 \mathrm{~min}$ to grow the particles ready for 
the main experimental work. This produced a uniform grey lustrous deposit; however, as expected, a significant deposition occurred on the feeder electrode, though the deposits could be removed by rubbing gently with a cloth. This was not surprising, particularly as the low potential pulses (totalling $4 \mathrm{~min}$ ) would have produced poor quality deposits on the feeder in the absence of electrolyte flow. The plating on the particles appeared to be adherent, with no visible production of a platinum particulate suspension when they were washed thoroughly in pure water; there was also no visible evidence of Pt sludge in the flow circuit. This was so even after extended running periods over which the catholyte became essentially colourless, with no turbidity evident in the solution or any sign of deposit in the translucent PVDF polymer flow circuit.

\subsection{Anode design}

The design of the oxidant-producing anode required for the complete process [2] was much simpler than that of the cathode. The species being produced were solution species $\left(\mathrm{I}_{3}{ }^{-}\right.$-Eq. (1)) from high concentrations of aqueous iodide ions, such that transport rates of iodide would never be current limiting, even on a 2-D anode, due to the low concentrations of metal being electrowon in the system.

$I_{3}^{-}+2 e^{-} \rightleftharpoons 3 I^{-}$

$E_{I_{3}^{-} / I^{-}}(\mathrm{SCE}) / V=0.291+0.0296 \log \left\{\left(I_{3}^{-}\right) /\left(I^{-}\right)^{3}\right\}$.

However, there were still some challenges and important design details. Dimensionally stable anodes (DSAs) often used in electrochemical reactors would be unsuitable anodes, since the platinum group metal (PGM) coating would be likely to dissolve in the iodide solutions under oxidising conditions. Hence, carbon was again chosen as the most suitable material, as it is not oxidised by the triiodide and the potentials required were well below those corresponding to oxygen evolution, which would otherwise have led to its rapid consumption.

The option for using graphite felt was included in the reactor design, as the high specific surface area would lower the risks of generating oxygen and those of solid iodine being formed. No specific performance tests were carried out on the anode, but it was used very successfully to generate tri-iodide during trials of the cathode. The carbon feeder electrode used in the experiments was a $1 \mathrm{~mm}$-thick graphite gasket material (Klinger AE5057708). The carbon felt used was a $1 / 2$ inch-thick sample (Le Carbone Great Britain Ltd, product code RVG4003) which filled the complete anode compartment area and once assembled had a $2 \mathrm{~mm}$ compression out of plane which aided contact with the feeder.

\subsection{Reactor performance experiments}

To minimise the number of experiments conducted and to maximise the useful resulting data, a factorial design of experiments was planned using a matrix of eight trials, which allowed for one factor at four levels and three factors at two levels [22]. This design of matrix allowed for an adequate range of cathode potentials to be used between kinetic controlled and mass transport controlled operation and the effect of a low and a high flow rates to be tested, with all possible combinations in eight experiments. The particulate cathode substrate used was pre-deposited with platinum, as described previously. Cyclic voltammetry [2] indicated that, over the range -0.1 to $-0.4 \mathrm{~V}$ (SCE), the reactor would be likely to switch from essentially total kinetic control to total mass transport control. Therefore, the matrix of parameter values shown in Table 1 was used for the trials.

In each case, the solution $\left(2 \mathrm{dm}^{3}\right)$ was prepared from $4 \mathrm{M} \mathrm{NaI}$ phosphate buffered to ca. pH 6 with the initial $\mathrm{PtI}_{6}{ }^{2-}$ concentration of $0.5 \mathrm{~mol} \mathrm{~m}{ }^{-3}$ (made using chloroplatinic acid), being typical of that, which would be generated by the leaching circuit. Details of the loading of the reactor cathode were:

average particle size $725 \mu \mathrm{m}$;

volume of particles ca. $66 \mathrm{~cm}^{-3}$;

number of particles ca. 104,000;

mass of particles ca. $47 \mathrm{~g}$;
Table 1 Experimental matrix used for investigating the performance of the electrochemical reactor for platinum deposition

\begin{tabular}{llll}
\hline Trial & Feeder potential, $E(\mathrm{SCE}) / V$ & Total flow rate $/ \mathrm{dm}^{3} \mathrm{~min}^{-1}$ & Control factor \\
\hline E1 & -0.1 & $0.3-0.35$ & 1 \\
E2 & -0.1 & $0.4-0.45$ & 2 \\
E3 & -0.2 & $0.3-0.35$ & 1 \\
E4 & -0.2 & $0.4-0.45$ & 2 \\
E5 & -0.3 & $0.3-0.35$ & 2 \\
E6 & -0.3 & $0.4-0.45$ & 1 \\
E7 & -0.4 & $0.3-0.35$ & 2 \\
E8 & -0.4 & $0.4-0.45$ & 1
\end{tabular}


surface area of particles, ca. $0.173 \mathrm{~m}^{2}$;

active cathode feeder area, $5.5 \times 10^{-3} \mathrm{~m}^{2}$.

The following parameters were logged during each experiment in LabView $^{\mathrm{TM}}$ using a National Instruments USB6009 Data Acquisition (DAQ) and control interface: cell potential difference, current, flow rate, and anode feeder potential. The measurement of anode feeder potential proved to be unreliable, but a value of only ca. $0.2 \mathrm{~V}$ (SCE) was measured initially during the first experiment, implying that the only reaction taking place was the generation of tri-iodide ions by reaction [19].

These data, together with concentrations in the reservoir of solution species determined by UV-Vis spectrophotometry of solution samples taken from the reservoir at regular intervals, allowed cathode charge yields $\left(\Phi_{\mathrm{Pt}}^{\mathrm{e}}\right)$ and specific electrical energy consumptions $\left(w_{\mathrm{Pt}}^{\mathrm{e}}\right)$ to be calculated over periods between samples during the experiments. As concentrations decreased to below the detection limit of the UV-Vis spectrophotometer (around $2 \times 10^{--}$ ${ }^{6} \mathrm{~mol} \mathrm{\textrm {dm } ^ { - 3 }}$ as the iodo-complexes have particularly high absorbance), some of the later samples were analysed by ICP-OES. In each experiment, the anolyte used was $4 \mathrm{M}$ iodide with a concentration of tri-iodide in excess of $20 \mathrm{~mol} \mathrm{~m}^{-3}$, such that the changes in equilibrium potential due to the small increase in tri-iodide concentration were negligible. All experiments were run for $5 \mathrm{~h}$ with nitrogen bubbling through the catholyte to keep the reservoir deoxygenated and well mixed; the former was not totally effective, as oxygen could diffuse through the polymeric flow circuit. Catholytes were deoxygenated to prevent the oxidation of the iodide to tri-iodide by the dissolved oxygen and the re-oxidation of any $\mathrm{Pt}^{\mathrm{II}}$ species formed in the bed, but not fully reduced to metal before leaving the cathode compartment.

The performance of the reactor could be measured against several criteria which are inter-related:

- specific electrical energy consumption $\left(w_{\mathrm{Pt}}^{\mathrm{e}}\right)$ and cathode charge yield $\left(\Phi_{\mathrm{Pt}}^{\mathrm{e}}\right)$;

- deposit morphology quality;

- rate of $\mathrm{Pt}^{\mathrm{IV} / \mathrm{II}}$ depletion.

Most of these performance criteria were assessed easily during operation of the reactor; however, deposit morphology could be assessed only afterwards using a scanning electron microscope (SEM).

\subsection{Reactor electrochemical performance simulation}

It was important to use simulation tools to understand the performance of a circulating bed and to aid future process research. Modelling was undertaken using a porous electrode model to predict the electrical behaviour of the electrodes being designed [23]. Equation (3) defines the potential gradients in the electrode (e) and electrolyte solution (s) phases [17]:

$\frac{d \phi_{\mathrm{e}(x)}}{d x}=\frac{-I_{\mathrm{e}(x)}}{\sigma_{\mathrm{e}} A_{\mathrm{f}}} \quad$ and $\quad \frac{d \phi_{\mathrm{s}(x)}}{d x}=\frac{-I_{\mathrm{s}(x)}}{\sigma_{\mathrm{s}} A_{\mathrm{f}}}$

which after nodal analysis and further manipulation leads to:

$\frac{d^{2} \phi_{\mathrm{e}(x)}}{d x^{2}}=A_{s} \frac{-j_{f(x)}}{\sigma_{\mathrm{e}}} \quad$ and $\quad \frac{d^{2} \phi_{\mathrm{s}(x)}}{d x^{2}}=A_{s} \frac{j_{f(x)}}{\sigma_{\mathrm{s}}}$.

Analytical solutions can be obtained to these expressions for the two extremes of transport limited and kinetically limited operation. However, using the Maple ${ }^{\mathrm{TM}}$ software, a numerical solution can be obtained for a more general case of the full spectrum from total kinetic control to total transport control, using the boundary conditions:

$$
\begin{aligned}
& \phi_{\mathrm{s}, x=0}=0, \quad \phi_{\mathrm{e}, x=0}=E_{\mathrm{feeder}}, \quad \frac{d \phi_{s}}{d x x_{x=0}}=0 \quad \text { and } \\
& {\frac{d \phi_{e}}{d x_{x=x_{1}}}}=0
\end{aligned}
$$

The effective conductivities of the solid electrode (e) and electrolyte solution (s) phases were calculated using Bruggeman's equation, as reviewed in Ref. [24]:

$\sigma_{\mathrm{s}}=\sigma_{\mathrm{s},(\text { bulk })}(\varepsilon)^{1.5}$
$\sigma_{\mathrm{e}}=\sigma_{\mathrm{e},(\text { bulk })}(1-\varepsilon)^{1.5}$.

A mass transport correlation (Eq. (8)) for fluidised beds was used [25], from which the mass transport coefficient was extracted using the definition of Sherwood number (Eq. (9)). However, the correlation was not intended for a circulating particulate bed and the values of the dimensionless groups do not lie within the ranges over which the relationship was developed. In the work reported by Lacin and Sarac [25], the density difference between the electrolyte and particles was $0.4 \mathrm{~g} \mathrm{~cm}^{-3}$, the particle diameter was about $3 \mathrm{~mm}$, and the lowest fluidising velocity was around $2.5 \mathrm{~m} \mathrm{~s}^{-1}$. Therefore, although the Schmidt and density numbers are similar, the Galileo and Reynolds number are several orders of magnitude smaller in the circulating bed case. Hence, when added to the complexity of the fluid flow, the relationship was capable of only approximate estimates of $k_{\mathrm{m}}$.

$\mathrm{Sh}=0.199 R e^{\frac{3}{5}} \mathrm{Ga}^{\frac{1}{10}} \mathrm{Mv}^{\frac{7}{2}} \mathrm{Sc}^{\frac{1}{3}}\left(\frac{d_{\mathrm{p}}}{E_{\mathrm{L}}}\right)^{\frac{3}{10}}\left(\frac{d_{\mathrm{p}}}{L_{\mathrm{Y}}}\right)^{\frac{-3}{4}}$

$k_{\mathrm{m}}=\frac{\operatorname{Sh} D_{\mathrm{Pt}^{\mathrm{IV}}}}{d_{\mathrm{p}}}$.

The model involved the following simplifying assumptions: 
- The potential varied only in the direction $(x)$ of current flow.

- Constant reactant concentration in the electrolyte through the electrode (i.e., negligible conversion per pass).

- Constant voidage which was taken to be that of a randomly packed bed of particles.

- Steady-state behaviour.

- The kinetics of all reactions were modelled by the Butler-Volmer equation, allowing for transport limitations, but in the absence of a migrational contribution to the overall transport rate, due to presence of excess supporting electrolyte.

The model, coded in the Maple ${ }^{\mathrm{TM}}$ software, included the kinetics of hydrogen evolution (Eq. (10)) and oxygen reduction (Eq. (12)) reactions, which competed with the metal deposition reactions (Eqs. (14), (16)).

$$
\begin{aligned}
& 2 \mathrm{H}^{+}+2 e^{-} \rightleftharpoons \mathrm{H}_{2(\mathrm{~g})} \\
& E_{\mathrm{H}^{+} / \mathrm{H}_{2(\mathrm{~g})}}(\mathrm{SCE}) / V=-0.245-0.0591 \mathrm{pH} \\
& -0.0296 \log \left(p\left(\mathrm{H}_{2}\right)\right) \\
& \mathrm{O}_{2(\mathrm{~g})}+4 \mathrm{H}^{+}+4 e^{-} \rightleftharpoons 2 \mathrm{H}_{2} \mathrm{O} \\
& E_{\mathrm{O}_{2(\mathrm{~g})} / \mathrm{H}_{2} \mathrm{O}}(\mathrm{SCE}) / V=0.984-0.0591 \mathrm{pH} \\
& +0.0148 \log \left(p\left(\mathrm{O}_{2}\right)\right) \\
& \mathrm{PtI}_{4}^{2-}+2 e^{-} \rightleftharpoons \mathrm{Pt}+4 \mathrm{I}^{-} \\
& E_{\mathrm{PtI}_{4}^{2-} / \mathrm{Pt}}(\mathrm{SCE}) / V=0.154+0.0296 \log \left(\mathrm{PtI}_{4}^{2-}\right) \\
& -0.118 \log \left(\mathrm{I}^{-}\right) \\
& \mathrm{PtI}_{6}^{2-}+2 e^{-} \rightleftharpoons \mathrm{PtI}_{4}^{2-}+2 \mathrm{I}^{-} \\
& E_{\mathrm{PtI}_{6}^{2-} / \mathrm{PtI}_{4}^{2-}}(\mathrm{SCE}) / V=0.160 \\
& +0.0296 \log \left\{\left(\mathrm{PtI}_{6}^{2-}\right) /\left(\mathrm{PtI}_{4}^{2-}\right)\right\}
\end{aligned}
$$

The 1-D model written in Maple ${ }^{\mathrm{TM}}$ code included the two step mechanism for the reduction of $\mathrm{PtI}_{6}{ }^{2-}$ to $\mathrm{Pt}$ via $\mathrm{PtI}_{4}{ }^{2-}$ (Eqs. (14) and (16)), using Butler-Volmer kinetic equations, allowing for kinetic, mixed, and transport control, based on the experimental data reported previously [2] and further cyclic voltammetry in $4 \mathrm{M}$ iodide.

Values for $j_{0}$ for the $\mathrm{Pt}^{\mathrm{IV}}-\mathrm{Pt}^{\mathrm{II}}$ and $\mathrm{Pt}^{\mathrm{II}}-\mathrm{Pt}^{0}$ were taken as 0.81 and $0.47 \mathrm{~A} \mathrm{~m}^{-2}$, respectively, with Tafel slopes of 90 and $400 \mathrm{mV}$ decade ${ }^{-1}$. The Tafel slope for the $\mathrm{Pt}^{\mathrm{II}}-\mathrm{Pt}^{0}$ reaction is particularly large but gave good agreement with experimental data. Figure 2 shows the modelled deposition of $\mathrm{Pt}$ from a $6.6 \mathrm{mM}$ solution of $\mathrm{PtI}_{6}{ }^{2-} / 4 \mathrm{M}$ KI solution with the corresponding experimental cyclic voltammetry data for scan two and eight. An offset of ca. $30 \mathrm{~mA} \mathrm{~cm}^{-2}$ due to a mass transport-limited reduction current density of significant tri-iodide content can also be seen.

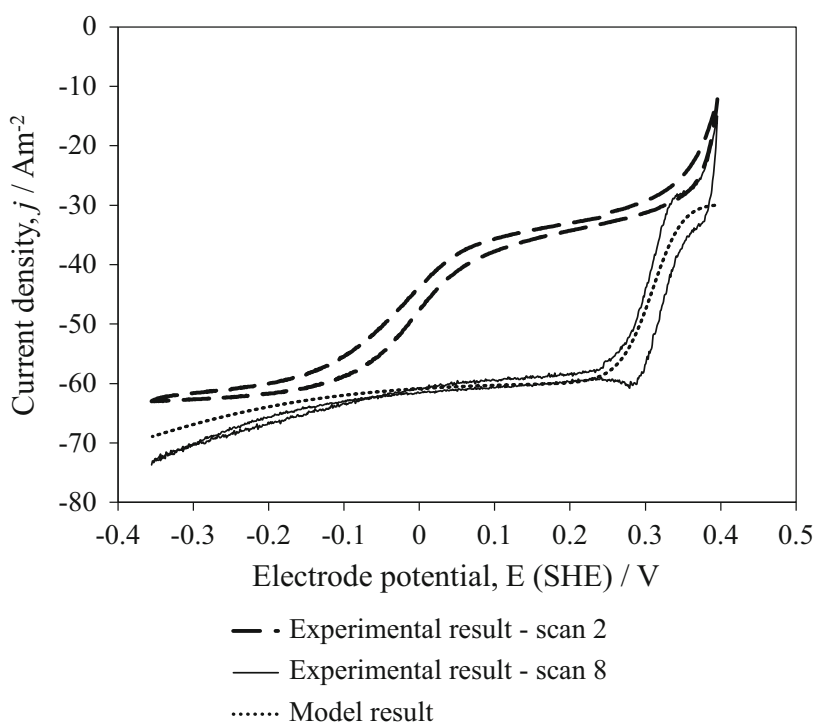

Fig. 2 Modelled Pt deposition on well-nucleated vitreous carbon disc electrode compared with experimental data. Experimental data measured for $4 \mathrm{M} \mathrm{KI}$, with $6.6 \mathrm{mM} \mathrm{PtI}_{6}{ }^{2-}$ and ca. $5.4 \mathrm{mM} \mathrm{I}_{3}{ }^{-}$. Scan rate $100 \mathrm{mV} \mathrm{s}^{-1}$ and a rotation rate of $10 \mathrm{~Hz}$. Deoxygenated by nitrogen prior to experiment

As reported previously [2], but for lower iodide concentrations, there was a significant nucleation overpotential before growth of the Pt deposit occurred. As the surface became well nucleated, the reduction of $\mathrm{Pt}^{\mathrm{IV}}$ to $\mathrm{Pt}^{\mathrm{II}}$ with a half-wave potential at ca. $0 \mathrm{~V}$ (SHE) in scan two became much more favourable than on the initial vitreous carbon surface, with the half-wave potential moving to ca. $0.3 \mathrm{~V}$ (SHE). The cyclic voltammogram for a poly-crystalline RDE of the same dimensions showed the fully nucleated behaviour from the first scan [2]. The kinetics of the final reduction to $\mathrm{Pt}^{0}$ appeared to remain slow. Besides the data reported previously by the present authors [2], we are unaware of any other studies of Pt deposition from iodide solutions having been published. However, the nucleation and growth kinetics of $\mathrm{Pt}$ from chloride onto vitreous carbon was also found to be slow [26], and inter alia due to competition between adsorbed halogen species and the deposition of Pt. Iodine/tri-iodide absorption on $\mathrm{Pt}$ is known to be strong [27-29] and so it very likely to have contributed to the slow kinetics exhibited. Hence, the Butler-Volmer type kinetic model proposed here is not mechanistically correct, as it does not consider surface coverage of adsorbed species, but using a large value for the Tafel slope, a predictively useful reactor model to aid design can still result.

It is interesting to note that unlike in strong iodide solutions, in which $\mathrm{Pt}^{\mathrm{II}}$ species have a wide region of stability and can be observed during experiments as a bright yellow complex, Yasin et al. [26] did not detect $\mathrm{Pt}^{\mathrm{II}}$ species as stable intermediates in $0.1 \mathrm{M}$ chloride. This is 
Fig. 3 Example model output showing a solid electrode and liquid electrolyte potential distributions in cathode, anode, membrane, and supporting separator, and b current density distributions though porous electrodes. For deposition from $0.5 \mathrm{mM} \mathrm{PtI}_{6}{ }^{2-}, 4 \mathrm{M}$ iodide phosphate buffered to ca. $\mathrm{pH} 6$ with a cathode feeder potential of $-0.4 \mathrm{~V}$ (SCE)
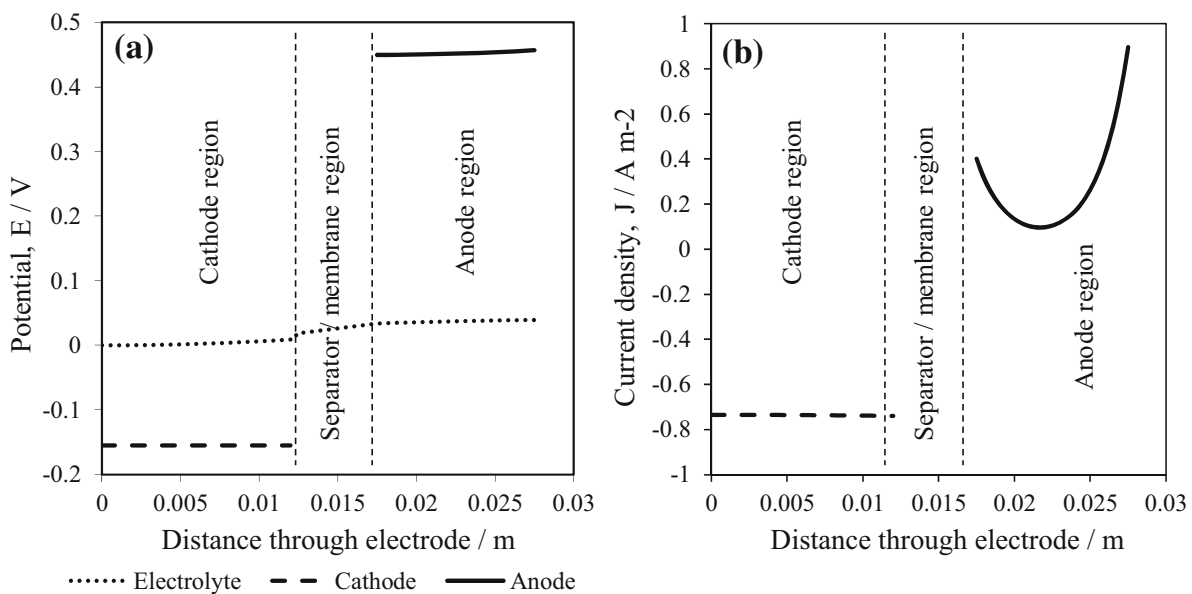

congruous with predictions of $\mathrm{E}-\mathrm{pH}$ diagrams for the two systems [1] for halide activities of $0.1 \mathrm{M}$.

The competing cathode reactions of tri-iodide reduction, oxygen reduction, and hydrogen evolution were also modelled, again using Butler-Volmer kinetic equations. Typical values for $j_{0}$ for oxygen reduction and hydrogen evolution on platinum in mild acid media were taken as $1 \times 10^{-8} \mathrm{~A} \mathrm{~m}^{-2}$ [30] and $3.4 \times 10^{-3} \mathrm{~A} \mathrm{~m}^{-2}$ [30], respectively, with the value of $\alpha$ taken as 0.5 . The kinetic parameters reported previously [1] for tri-iodide reduction were used. The electrical conductivity of $4 \mathrm{M}$ iodide was estimated to be $46 \mathrm{~S} \mathrm{~m}^{-1}$ [31], with the substrate taken to have a much higher conductivity of $10^{4} \mathrm{~S} \mathrm{~m}^{-1}$. Since the substrate conductivity was several orders of magnitude greater than that of the electrolyte, the results were insensitive to the exact value used. The diffusion coefficients were calculated using unhydrated ion sizes estimated from radii data and the kinematic viscosity of $4 \mathrm{M}$ KI (ca. $0.61 \times 10^{-6} \mathrm{~m}^{2} \mathrm{~s}^{-1}$ ) [31] giving good agreement with empirical values that were calculated from the results of RDE experiments. The mass transport coefficients were estimated using the correlation (Eq. (8)) for fluidised beds [25]. This led to predictions of fairly low mass transport rate coefficients of $0.38 \times 10^{-5} \mathrm{~m} \mathrm{~s}^{-1}$ for the Pt species, $0.44 \times 10^{-5} \mathrm{~m} \mathrm{~s}^{-1}$ for tri-iodide, and $1.2 \times 10^{-5} \mathrm{~m} \mathrm{~s}^{-1}$ for oxygen. However, these predictions were congruous with the experimental results for the bed under mass transport controlled operation. The concentrations of triiodide and oxygen in the catholyte were taken as $1.5 \times 10^{-5} \mathrm{M}$ and $5 \times 10^{-5} \mathrm{M}$, respectively, given the steady-state currents detected at the end of the experiments and the measured tri-iodide concentration (determined by UV-Vis spectrophotometry). Figure 3 shows an example output from the model illustrating: (a) the electrolyte and electrode potential distributions and (b) the current density, predicted for a particular set of conditions used experimentally. This clearly shows the contributions to the overall cell potential difference from the anode and cathode and the effect of the different solid phase conductivities of the carbon felt anode and the particulate cathode.

\subsection{Electrochemical reactor circuit details}

The flow circuit used for determining the performance of the electrochemical reactor was designed as part of a laboratory scale plant for demonstrating the whole process. The reactor was not designed for continuous harvesting of particles, but it was envisaged that a weir at the top of the reactor could be incorporated easily, allowing the particles to be transported out of the reactor and caught in a separator at the base of the weir.

The reactor was designed to operate with anolyte and catholyte volumes of $2-2.5 \mathrm{dm}^{3}$, which was a convenient volume for the reactor size and the dead volume of the pipe work needed to complete the circuit. The level of the base of the electrochemical reactor was above the level of the $2.5 \mathrm{dm}^{3}$ mark on the electrolyte reservoirs, such that when the pumps were stopped, the reactor would drain naturally back into the reservoirs, lowering the risk of any unwanted chemical reactions occurring and allowing the solutions to be pumped out with minimal hold up of solution in the circuits. Images of the complete reactor as designed and as built are shown in Fig. 4, which also show the complete process with leach reactors.

\section{Results and discussion}

\subsection{Hydrodynamic performance}

Figure 5 shows the effect of electrolyte solution flow rates from $0.3-0.9 \mathrm{dm}^{3} \mathrm{~min}^{-1}$ on the results of simulating the spatial distribution of particulate (cathode) solids using the Fluent ${ }^{\mathrm{TM}}$ software for the reactor geometry. At the lowest 
Fig. 4 Electrochemical reactor, including whole process circuit as designed and as built in practice
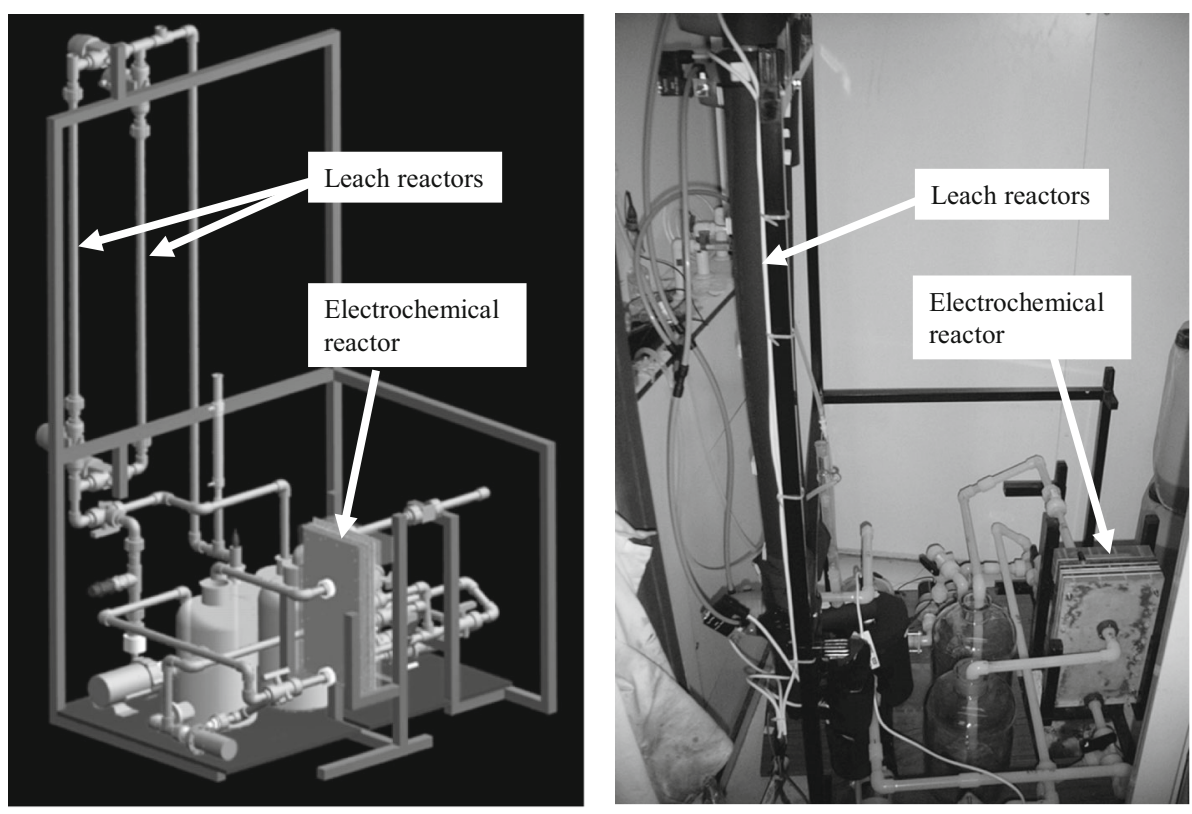

Fig. 5 Granular fraction of particle bed electrode for graphite electrode material in $4 \mathrm{M} \mathrm{KI}$ solution for different flow rates of electrolyte. a $0.3 \mathrm{dm}^{3} \min ^{-1}$, b $0.5 \mathrm{dm}^{3} \mathrm{~min}^{-1}$, c $0.7 \mathrm{dm}^{3} \min ^{-1}$, and d $0.9 \mathrm{dm}^{3} \mathrm{~min}^{-1}$. Scale bar shows granular fraction. Simulations are time varying and are shown at a point where a steady velocity field has been reached (typically $30 \mathrm{~s}$ ). Please refer to online edition for colour images

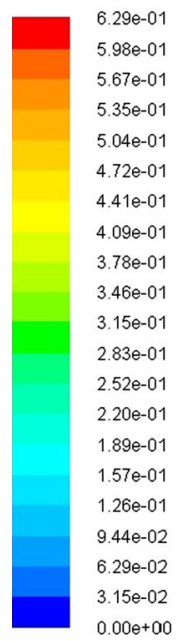

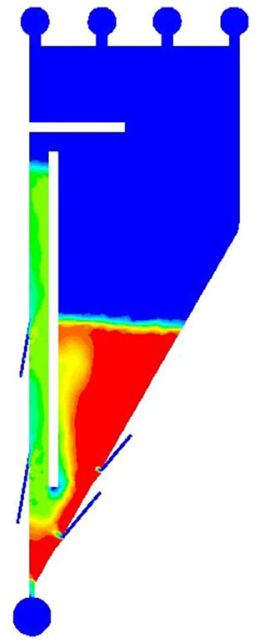

(a)

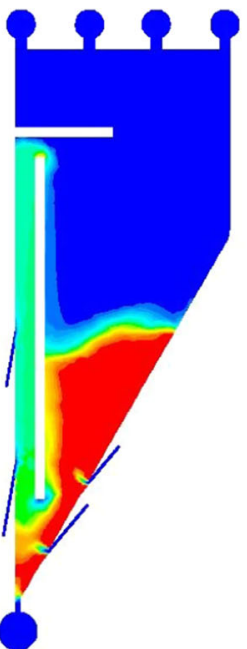

(b)

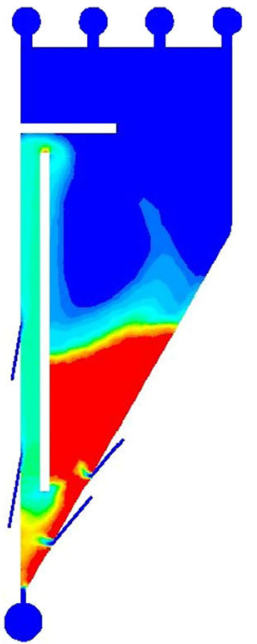

(c)

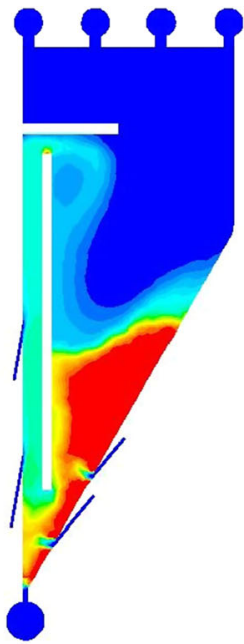

(d) flow rate simulated, the flow was predicted to be insufficient to cause circulation and a fluidised bed was formed in the draft tube. In the two intermediate cases, stable circulation of particles was achieved with a slowly descending packed bed formed in the inclined section, without 'dead spots' of no particle movement. At the highest flow rate, a plot (Fig. 6) of granular fraction velocities indicated that particle loss was likely through the furthest outlet, shown to the right. Figure 7 shows the electrolyte velocity alone for the cases of successful circulation. If the velocities of both the electrolyte and granular phase are interrogated more closely (Fig. 8), it can be seen that within the conditions simulated, once the bed has been set up and particle circulation has been achieved, the granular and electrolyte velocities within the bed are largely invariant with electrolyte flow rate. Increasing electrolyte flow merely serves to increase the size of the electrolyte and granular fraction vortex above the bed; too large, a flow rate results in the loss of the granular fraction through the outlets.

Experiments with water alone and no anode or membrane showed that, as predicted, the reactor could be controlled to remove all dead zones and the bed descending speed could be controlled by varying the flow to the appropriate manifold. As shown in Fig. 6, a large particle vortex was formed above the bed and led to an incline on the top of the descending packed bed. This was experienced in practice, but the residence time of particles in this vortex appeared short and helped to distribute particles across the top of the descending packed bed, aiding rather than hindering performance. Tests with the $4 \mathrm{M}$ iodide 
Fig. 6 Granular fraction velocity vectors for successfully circulating particulate bed electrode for graphite electrode material in $4 \mathrm{M}$ KI solution for different flow rates of electrolyte. a $0.5 \mathrm{dm}^{3} \mathrm{~min}^{-1}$, b $0.7 \mathrm{dm}^{3} \min ^{-1}$, and c) $0.9 \mathrm{dm}^{3} \mathrm{~min}^{-1}$. Scale bar shows granular fraction velocity magnitude in $\mathrm{m} \mathrm{s}^{-1}$.

Simulations are time varying and are shown at a point where a steady velocity field has been reached (typically $30 \mathrm{~s}$ ). Please refer to online edition for colour images

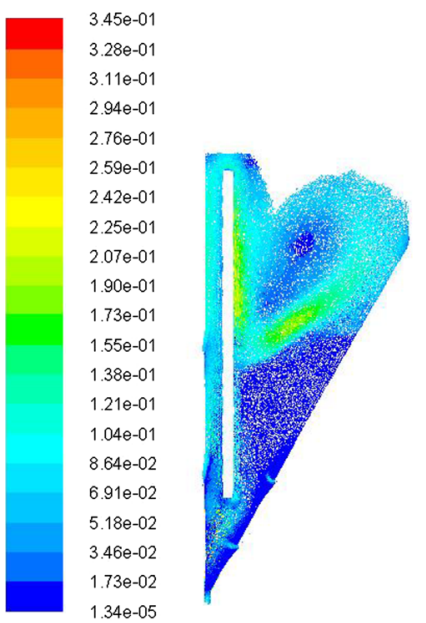

(a)

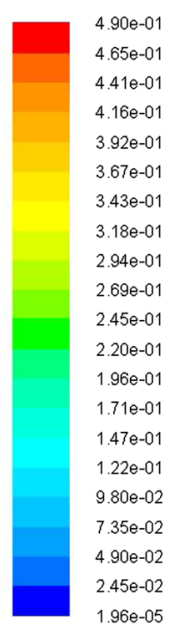

Loss of particles from outlet

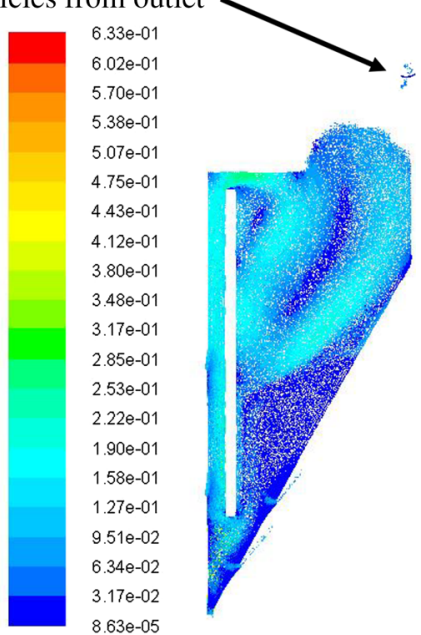

(c)

Fig. 7 Electrolyte velocity vectors for successfully circulating particulate bed electrode for graphite electrode material in $4 \mathrm{M} \mathrm{KI}$ solution for different flow rates of electrolyte. a $0.5 \mathrm{dm}^{3} \mathrm{~min}^{-1}$, b $0.7 \mathrm{dm}^{3} \min ^{-1}$, and c $0.9 \mathrm{dm}^{3} \min ^{-1}$. Scale bar shows electrolyte velocity magnitude in $\mathrm{m} \mathrm{s}^{-1}$.

Simulations are time varying and are shown at a point where a steady velocity field has been reached (typically $30 \mathrm{~s}$ ). Please refer to online edition for colour images

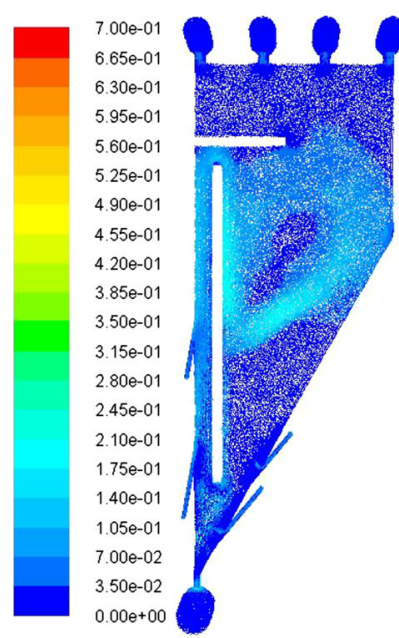

(a)
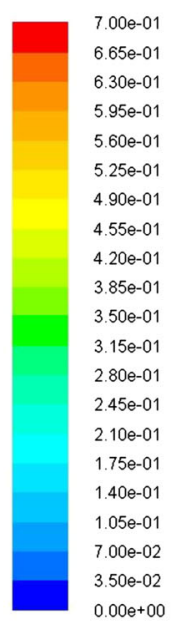

(b)

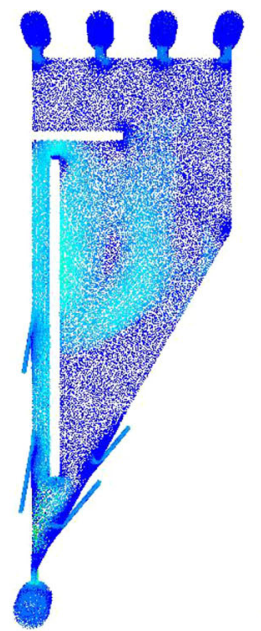

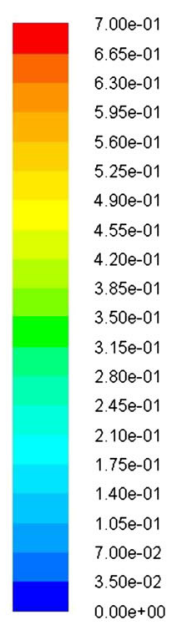

(c) electrolyte demonstrated that successful particle flow was achieved at a total flow rate of $0.3-0.5 \mathrm{dm}^{3} \mathrm{~min}^{-1}$, without a significant loss of particles from the system. This was slightly lower than the range predicted by the Fluent ${ }^{\mathrm{TM}}$ simulation and was due mainly to significant porosity in the (natural) graphite particles decreasing their density; that porosity is shown in Fig. 10 in the following section. However, as the density difference increased with time/deposit thickness, the flow rate of electrolyte required for successful operation would steadily increase.

\subsection{Reactor operation}

Figure 9a, b shows the time dependences of concentration, $\Phi_{\mathrm{Pt}}^{\mathrm{e}}$ and $w_{\mathrm{Pt}}^{\mathrm{e}}$, for the experiments averaged for each potential used and for the flow rates, to determine the individual effects of each parameter. The effect of feeder electrode potential on $\mathrm{Pt}^{\mathrm{II} / \mathrm{IV}}$ concentration decays was due to the progressive transition from kinetic to mass transport-limited deposition as the potential was decreased. The effect of changing the flow rate from the low to the high levels was shown not to be significant, since the variations shown in Fig. 9b were reflected almost exactly in the control, indicating errors, probably from slight inconsistencies in the flow of particles, in some of the data points rather than a real effect. This is consistent with the simulations showing a little effect on particle and electrolyte velocity in the bed and consequently on mass transport rates over the range of inlet electrolyte flow rates that would produce successful circulation. Hence, the values of mass transport rate coefficients in the active bed must have remained essentially unaltered for the two flow rates, due to the complexity of the distributions in particle velocities and concentrations (Figs. 5, 6, 7, 8). The values of $\Phi_{\mathrm{Pt}}^{\mathrm{e}}$ and $w_{\mathrm{Pt}}^{\mathrm{e}}$ in Fig. 9 varied 

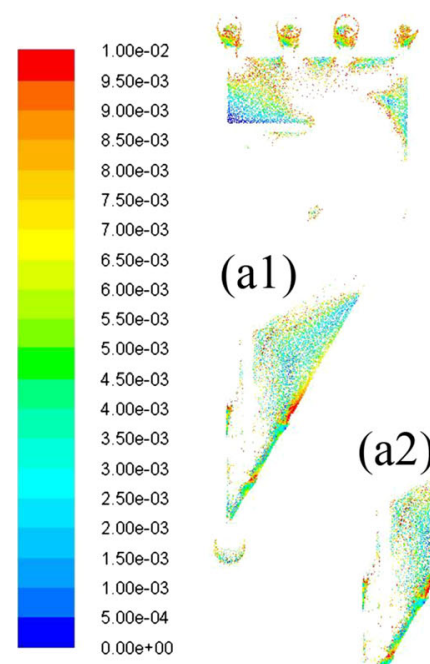

(a1)

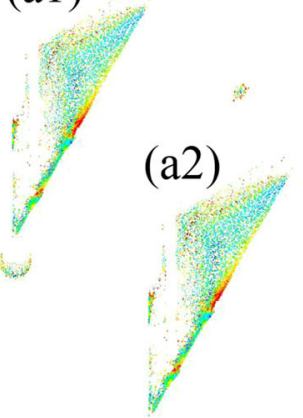

Fig. 8 Electrolyte and granular velocity vectors for successfully circulating particulate bed electrode for graphite electrode material in $4 \mathrm{M} \mathrm{KI}$ solution for different flow rates of electrolyte on a common $0.01 \mathrm{~m} \mathrm{~s}^{-1}$ maximum scale bar. (a1) $0.5 \mathrm{dm}^{3} \mathrm{~min}^{-1}$ electrolyte phase, (b1) $0.7 \mathrm{dm}^{3} \mathrm{~min}^{-1}$ electrolyte phase, and (c1) $0.9 \mathrm{dm}^{3} \mathrm{~min}^{-1}$

dramatically with feeder potential. The value of $\Phi_{\mathrm{Pt}}^{\mathrm{e}}$ defined by

$\Phi_{\mathrm{Pt}}^{\mathrm{e}}=\frac{Q_{\mathrm{th}}}{Q_{\mathrm{exp}}}=\frac{\Delta\left[\mathrm{Pt}^{\mathrm{II}}\right] V v_{e} F}{Q_{\mathrm{exp}}}$

was based on the two electron (i.e. the electron stoichiometry, $v_{\mathrm{e}}=2$ ) reduction of $\mathrm{Pt}^{\mathrm{II}}$ directly to $\mathrm{Pt}^{0}$, such that charge used to reduce $\mathrm{Pt}^{\mathrm{IV}}$ to only $\mathrm{Pt}^{\mathrm{II}}$ was effectively considered a loss reaction at the start of the experiment, since practical considerations in the UV-vis spectroscopy required the conversion of $\mathrm{Pt}^{\mathrm{IV}}$ to $\mathrm{Pt}^{\mathrm{II}}$ and the reduction of any highly absorbing $\mathrm{I}_{3}{ }^{-}$present. This was dominant at the start of the experiments with less negative cathode feeder potentials, resulting in a transient accumulation of the $\mathrm{Pt}^{\mathrm{II}}$, hence producing artificial maxima in $\Phi_{\mathrm{Pt}}^{\mathrm{e}}$ and minima in $w_{\mathrm{Pt}}^{\mathrm{e}}$. As those potentials were decreased, the reactions became progressively more transport controlled, the fraction of $\mathrm{Pt}^{\mathrm{II}}$ being produced decreased, shifting the $\Phi_{\mathrm{Pt}}^{\mathrm{e}}$ maxima/ $w_{\mathrm{Pt}}^{\mathrm{e}}$ minima to shorter times. Initially, higher concentrations of tri-iodide ions were probably also present in the solutions, due to the method by which they were made, allowing atmospheric oxygen ingress, so decreasing charge yields at the start due to reaction (1) contributing to the measured current. The initial peak in $\Phi_{\mathrm{Pt}}^{\mathrm{e}}$ over the first few minutes for the experiment at $-0.1 \mathrm{~V}$ (SCE) can be explained by the presence of a small amount of Ag contaminant, which is present on the substrate initially from the development work; Ag dissolved, reducing a little $\mathrm{PtI}_{6}{ }^{2-}$ and so giving an apparently higher charge yield/ current efficiency.

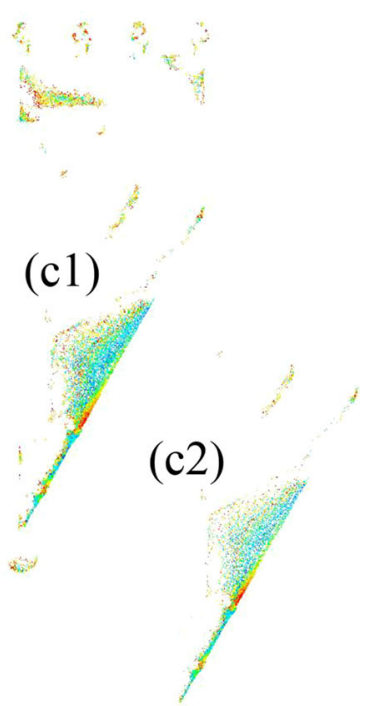

(b2)

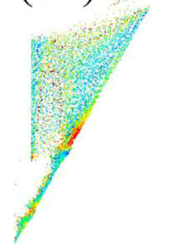

electrolyte phase. (a2) $0.5 \mathrm{dm}^{3} \mathrm{~min}^{-1}$ granular phase, (b2) $0.7 \mathrm{dm}^{3}$ $\mathrm{min}^{-1}$ granular phase, and (c2) $0.9 \mathrm{dm}^{3} \mathrm{~min}^{-1}$ electrolyte granular. Simulations are time varying and are shown at a point where a steady velocity field has been reached (typically $30 \mathrm{~s}$ ). Please refer to online edition for colour images

Charge yields decreased, so specific electrical energy consumptions increased, as dissolved platinum was depleted, and loss reaction rates became progressively more significant; (partially kinetically controlled) oxygen reduction and mass transport-limited reduction of a small circulating load of tri-iodide produced by dissolved oxygen oxidising iodide ions were the primary loss processes. The total current of these loss reactions was predicted to be 9 , 25,39 , and $41 \mathrm{~mA}$ for the feeder potentials $-0.1,-0.2$, -0.3 , and $-0,4 \mathrm{~V}$ (SCE), respectively. The tri-iodide present could be detected visually by the faint characteristic yellow-brown colour, which when measured by UVVis spectrophotometry gave the characteristic tri-iodide spectra with an absorbance indicating a concentration of ca. $1.5 \times 10^{-5} \mathrm{M}$.

Overall, the results showed that the reactor was capable of removing the platinum effectively down to about $170 \mathrm{ppb}$ in $5 \mathrm{~h}$. Running one of the experiments for an extra $5 \mathrm{~h}$ showed no incremental reduction in $\mathrm{Pt}^{\mathrm{IV} / \mathrm{II}}$ concentrations over that time, probably due to the slow diffusion of Pt from the Pt-rich electrolyte in the reference electrode compartment. This was detected by a strong gradient in colour in that compartment at the end of the experiments.

The difference in deposit morphologies as the deposition was changed from kinetic to mass transport control is evident from the SEM images shown in Fig. 10, which also shows the surface of a fresh graphite particle. Even for mass transport controlled deposition at a feeder cathode potential of $-0.4 \mathrm{~V}$ (SCE), the deposit was rough though not dendritic, still producing a coherent, adherent coating. 
Fig. 9 Response of reactor to four levels of cathode feeder potential and two levels of catholyte flow rate when depositing platinum from $2 \mathrm{dm}^{-3}$ of $0.5 \mathrm{mM} \mathrm{PtI}_{6}^{2-}, 4 \mathrm{M}$ iodide phosphate buffered to ca. $\mathrm{pH} 6$ at room temperature. (a) Effect of varying feeder potential averaged for the two flow conditions used to isolate effect of feeder potential.

(b) Effect of varying the overall catholyte flow averaged for feeder potentials applied to isolate the effect of flow rate (a)
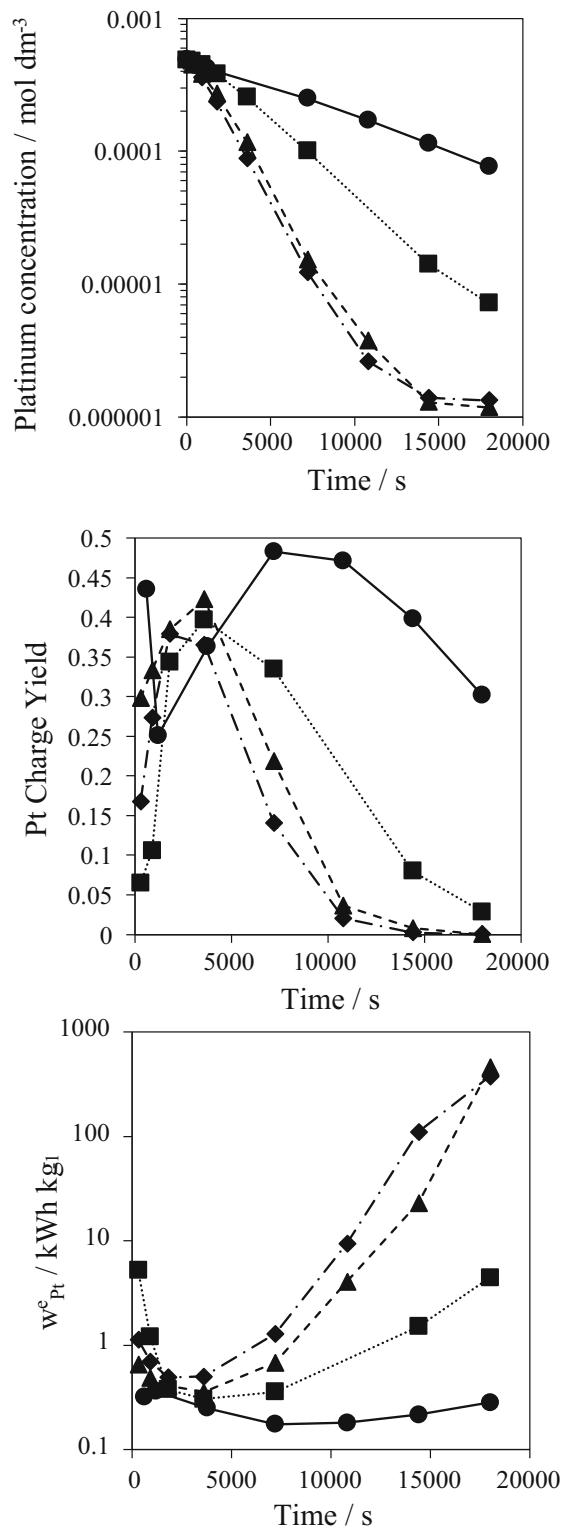

$\longrightarrow$

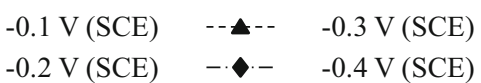

(b)
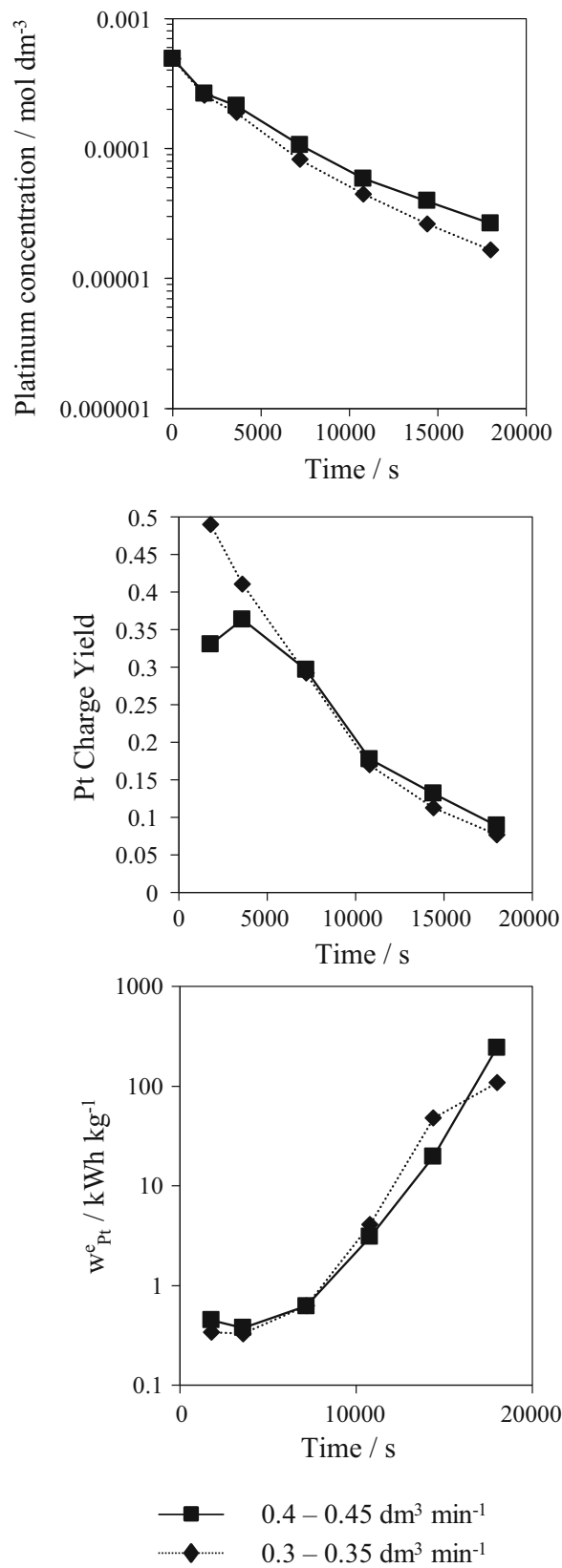

It is probable that, when operating at the mass transport controlled limit, deposit morphologies had been improved by the continuous collisions between particles during their motion. The first experiments conducted were those under kinetic control, when distinct islands of Pt were obvious. In the later experiments at -0.2 and $-0.4 \mathrm{~V}$ (SCE), these islands coalesced, giving a more even but rougher coating. The increased thickness of the deposit was also confirmed qualitatively by the energy-dispersive X-ray spectroscopy microanalysis of the surface, which for the later experiments, and showed far less intensity of X-ray emission from the carbon substrate. The image of the fresh graphite surface shows that its rough surface was less than ideal for deposition, but did not prevent successful deposition.

Operation of the bed without any particulate substrate was attempted for a short period, using a freshly prepared solution. The results confirmed the importance of using a high surface area cathode, in the absence of which currents of $\leq$ ca. $2 \mathrm{~mA}$ were measured, even with a cathode potential of $-0.4 \mathrm{~V}$ (SCE), whereas under the same conditions $\geq$ ca., $150 \mathrm{~mA}$ were achieved with the bed as can be seen in Fig. 12. 
Fig. 10 SEM images at high magnification of typical deposit morphologies on graphite particles after experiments at high flow rate $\left(0.4-0.45 \mathrm{dm}^{3}\right.$ $\min ^{-1}$ )
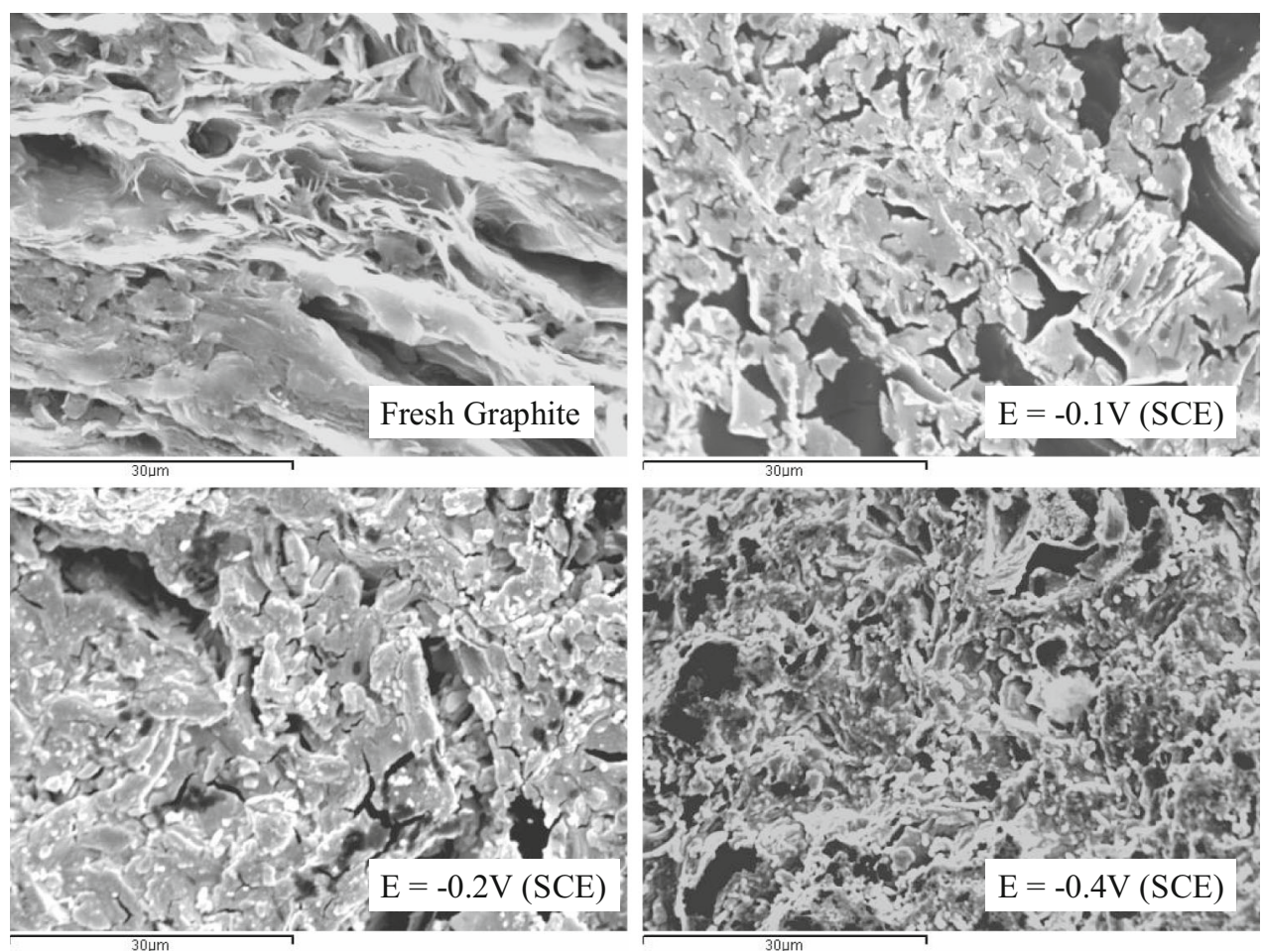

\subsection{Reactor simulation}

Figure 11 shows the results of modelling the time dependence of concentrations of platinum species for constant cathode feeder potentials, with the reactor operating in batch recycle mode. The model predictions of concentrations fitted the experimental data quite well; $\mathrm{PtI}_{4}{ }^{2-}$ concentrations accumulated in the solution to produce maxima
Fig. 11 Comparison of predicted time-dependent concentrations of platinum with experimental results for different cathode feeder potentials. a $-0.1 \mathrm{~V}$ (SCE), b $-0.2 \mathrm{~V}(\mathrm{SCE})$, c $-0.3 \mathrm{~V}$ (SCE), and d $-0.4 \mathrm{~V}$ (SCE). Experimental results for flow rates between $0.4-0.45 \mathrm{dm}^{3} \mathrm{~min}^{-1}$
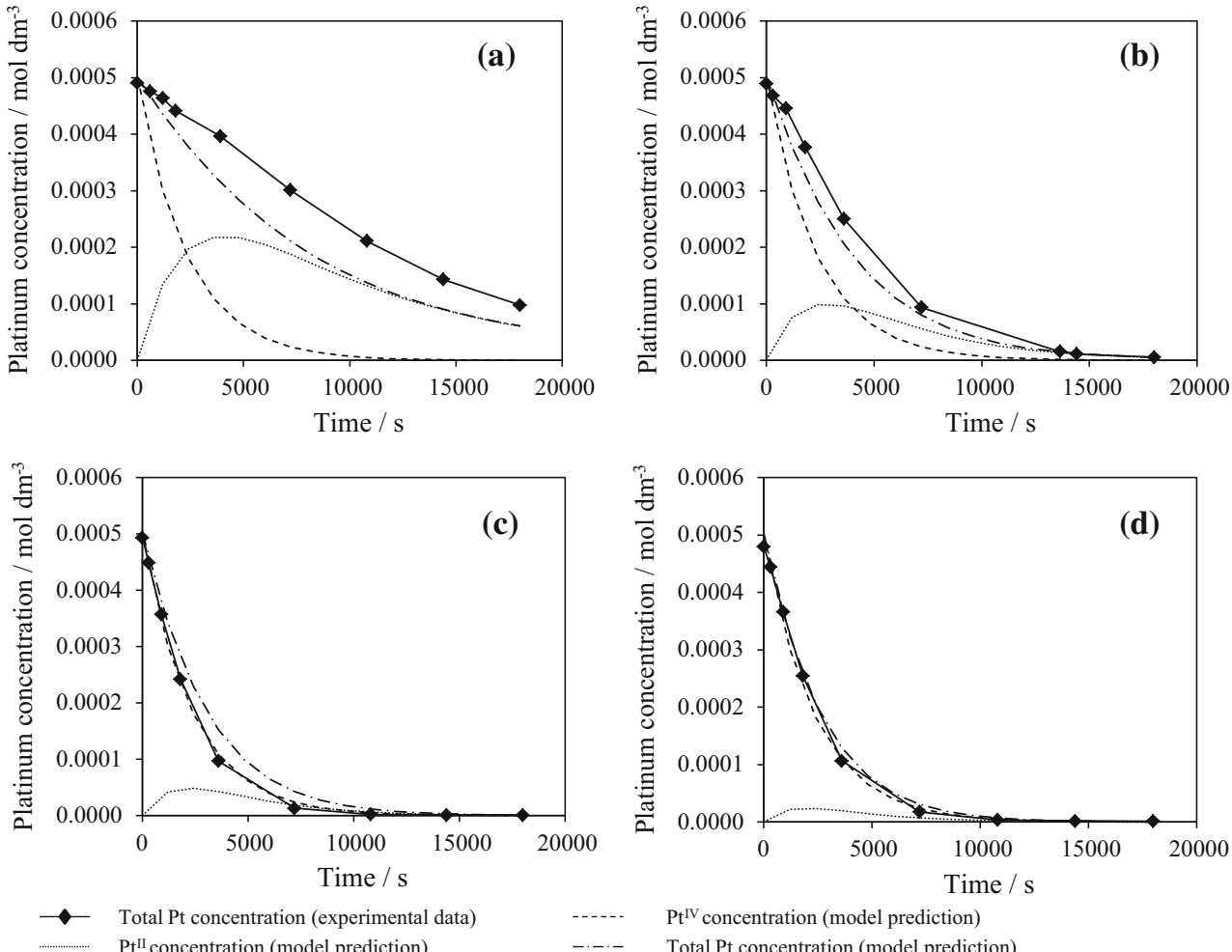
Fig. 12 Comparison of predicted time-dependent reactor currents with experimental results for different cathode feeder potentials. a $-0.1 \mathrm{~V}$ (SCE), b $-0.2 \mathrm{~V}$ (SCE), c $-0.3 \mathrm{~V}$ (SCE), and d $-0.4 \mathrm{~V}$ (SCE). Experimental results for flow rates between $0.4-0.45 \mathrm{dm}^{3} \mathrm{~min}^{-1}$
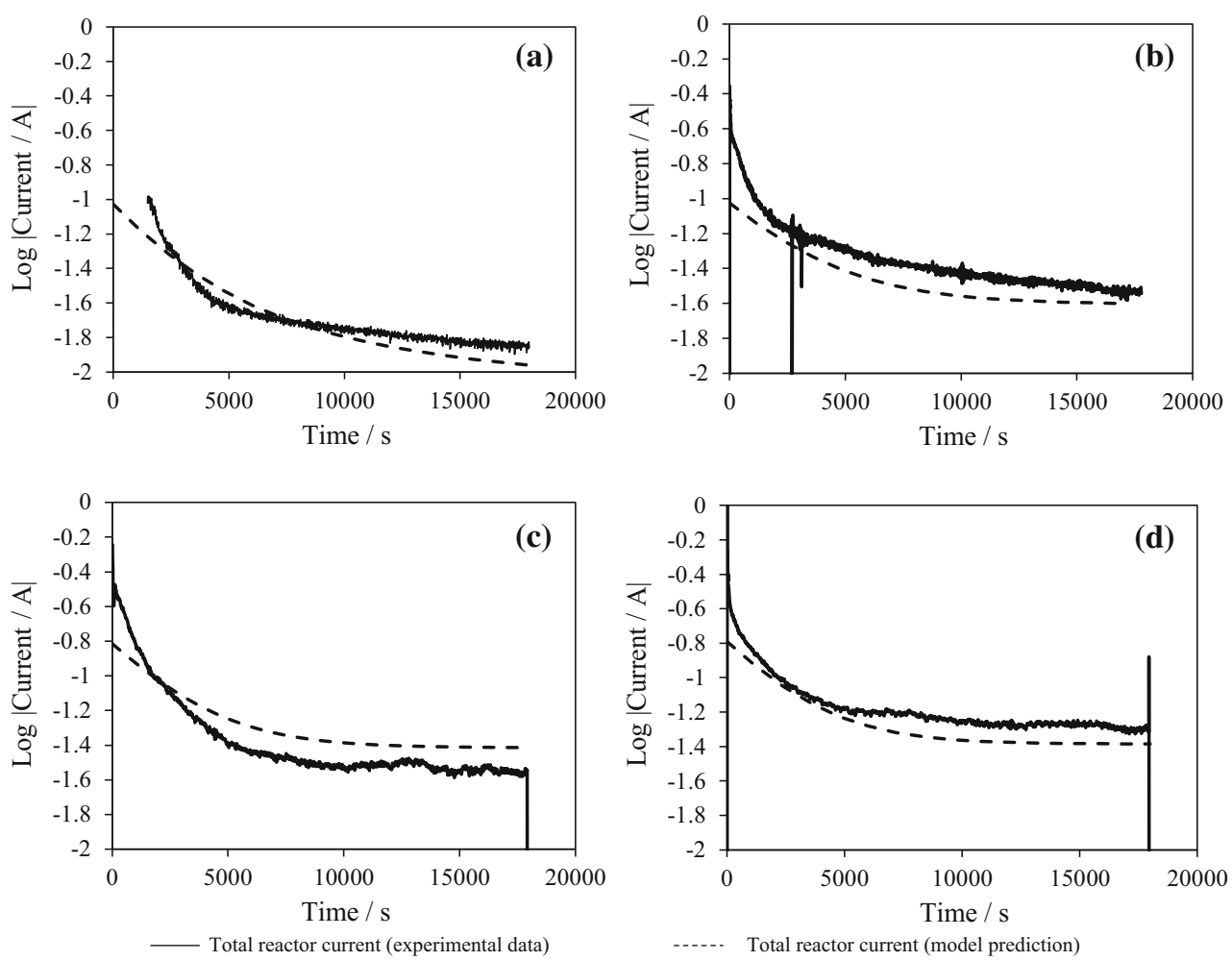

Fig. 13 Predictions of the timedependent charge yield a and specific electrical energy consumption, $\mathbf{b}$ for the deposition of Pt from $2 \mathrm{dm}^{-3}$ of $0.5 \mathrm{mM} \mathrm{PtI}_{6}{ }^{2-}, 4 \mathrm{M}$ iodide solution in the reactor. Experimental results for feeder electrode potentials of

$-0.1 \mathrm{~V}(\mathrm{SCE})$ and

$-0.4 \mathrm{~V}$ (SCE) are also overlaid. Experimental results for flow rates between $0.4-0.45 \mathrm{dm}^{3}$ $\min ^{-1}$

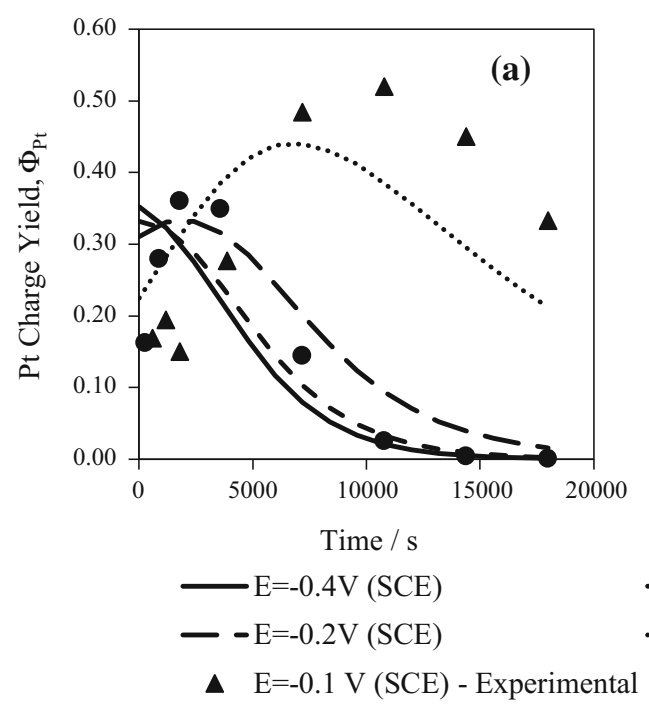

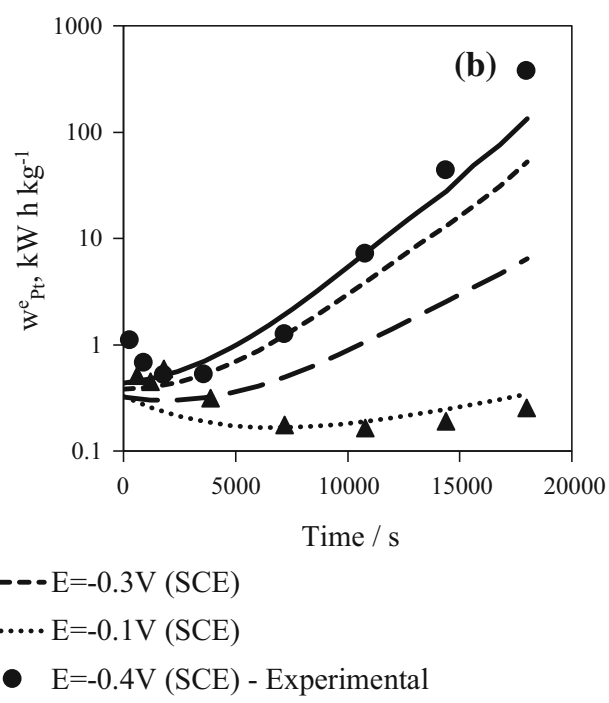

which were particularly evident when the reaction $\mathrm{Pt}^{\mathrm{II}}-\mathrm{Pt}^{0}$ was kinetically controlled, whilst the reaction $\mathrm{Pt}^{\mathrm{IV}}-\mathrm{Pt}^{\mathrm{II}}$ was always transport controlled for the range of potentials used.

The measured reactor currents in Fig. 12 were in reasonable agreement with model-predicted currents, but in each case, there was a section over the first 1500-2000 s for which high concentrations of $\mathrm{I}_{3}{ }^{-}$species, not considered in the model, were reduced. This can be explained when it is considered that the solutions were made in advance and used at least $12 \mathrm{~h}$ later, during which time atmospheric oxygen dissolved in the solution would have oxidised some iodide ions, producing a significant initial tri-iodide concentration. This would have been much greater than the steady-state concentrations obtained at the end of the experiments.

Figure 13 shows the time dependences of charge yields and specific electrical energy consumptions, calculated from model-predicted currents for the $\mathrm{Pt}^{\mathrm{II}}$ to $\mathrm{Pt}^{0}$ reduction. These data exhibited the expected responses for a process in which the rates of the competing reactions were constant for each potential, whilst the platinum reduction rate decreased as the platinum concentration decayed. When 
the excess initial amounts of tri-iodide present in the solution were considered, these predictions were in good agreement with the experimental data for charge yields and specific electrical energy consumptions shown in Fig. 9, as illustrated by the overlaid data for the two extremes of feeder electrode potential.

\section{Conclusions}

An electrochemical reactor incorporating a circulating (graphite) particulate bed electrode was designed and developed, its performance characterised, and shown to be effective for the proposed platinum recovery process. $\mathrm{I}_{3}{ }^{-}$ species were generated anodically to dissolve Pt in an external reactor as $\mathrm{PtI}_{6}{ }^{2-}$ ions, coupled to their cathodic electrodeposition from neutral aqueous $4 \mathrm{M}$ KI solutions, typically depleting solutions from 68,700 to $170 \mathrm{ppb}$ in $5 \mathrm{~h}$. A reactor model based on the Newman-Tobias porous electrode model was developed, written in Maple ${ }^{\mathrm{TM}}$ code, that predicted successfully the progressive switch between kinetic and mass transport control with decreasing cathode feeder potential.

The morphologies of the Pt deposits produced were coherent and adherent, even when deposited under mass transport control, probably due to the mechanical interactions between particles. Scanning electron micrographs showed that deposit morphologies transitioned from a smooth plate-like deposit to a rougher textured deposit as the deposition was changed from a kinetically to transportlimited process, by decreasing the feeder electrode potential.

The model and the experimental results both showed that the reactor could be operated with charge yields of ca. $45 \%$, corresponding to specific electrical energy consumptions of ca. $1.0 \mathrm{~kW} \mathrm{~h} \mathrm{~kg}{ }^{-1} \mathrm{Pt}$. Hence, the corresponding electrical energy costs were clearly insignificant compared with the value of the metal recovered, but may be important in the trade-off between overall process costs and recovery rate. Therefore, the exact optimal conditions would depend exactly on the design objectives, but it is clear that pumping rates would need to be carefully controlled to the minimum required to achieve successful circulation as any increase has little positive affect.

Acknowledgments The authors thank the UK EPSRC and Johnson Matthey for a CASE studentship for RJD. Details of the data and how to request access are available at Lancaster University research portal. Please follow DOI link http://dx.doi.org/10.17635/lancaster/ researchdata/101 for further details.

Open Access This article is distributed under the terms of the Creative Commons Attribution 4.0 International License (http://crea tivecommons.org/licenses/by/4.0/), which permits unrestricted use, distribution, and reproduction in any medium, provided you give appropriate credit to the original author(s) and the source, provide a link to the Creative Commons license, and indicate if changes were made.

\section{References}

1. Dawson RJ, Kelsall GH (2007) Recovery of platinum group metals from secondary materials. I. Palladium dissolution in iodide solutions. J Appl Electrochem 37(3):3-14

2. Dawson RJ, Kelsall GH (2013) Pt dissolution and deposition in high concentration aqueous tri-iodide/iodide solutions. ECS Electrochem Lett 2(11):D55-D57

3. Angelidis TN (2001) Development of a laboratory scale hydrometallurgical procedure for the recovery of $\mathrm{Pt}$ and $\mathrm{Rh}$ from spent automotive catalysts. Top Catal 16(1-4):419-423

4. Bonucci JA, Parker PD (1984) Recovery of PGM from automobile catalytic converters. In: Precious metals: mining, extraction and processing. Conference on the metallurgical society, Warrendale, pp 27-29

5. Letowski FK, Distin PA (1989) Development of aluminum chloride leach process for platinum and palladium recovery from scrapped automotive catalysts. (retroactive coverage). In: Precious metals. Conference in the international precious metals institute, Pensacola, pp 41-49

6. Letowski FK, Distin PA (1985) Platinum and palladium recovery from spent catalysts by aluminum chloride leaching. In: Recycle and secondary recovery of metals. Conference on the metallurgical society, Warrendale, pp 735-745

7. Bautista RG, Yue L, Tyson DR (1988) Platinum and palladium recovery from spent automobile catalysts leaching with ( $\mathrm{HCL}):\left(\mathrm{HNO}_{3}\right)$ in a packed and fluidized bed in precious and rare metal technologies Conference in Elsevier, Amsterdam, pp 365-380

8. Kim J, Park H, Lee H, Kim S, et al. (1994) Recovery of precious metals from spent catalyst generated in domestic petrochemical industry. In: Metallurgical processes for the early twenty-first century. Conference on the minerals, metals and materials society, Warrendale, pp 979-989

9. Patel A, Dawson R (2015) Recovery of platinum group metal value via potassium iodide leaching. Hydrometallurgy 157:219-225

10. Patel A, Harding A, Dawson R, Recovery of platinum group metals from end of life PEMFC. In: Palmas S, Mascia M, Vacca A (eds) 10th Esee: European symposium on electrochemical Engineering, pp 43-48

11. Robinson D, MacDonald S, Todaro F (2003) Commercial development of a descending packed bed electrowinning cell. In: Electrochemistry in mineral and metal processing VI. Conference on the electrochemical society, Pennington, pp 2003-2018

12. Scott K (1981) Metal recovery using a moving-bed electrode. J Appl Electrochem 11(3):339-346

13. Verma A, Salas-Morales JC, Evans JW (1997) Spouted bed electrowinning of zinc. II. Investigations of the dynamics of particles in large thin spouted beds. Metall Mater Trans B 28B(1):69-79

14. Stankovic VD, Stankovic S (1991) An investigation of the spouted bed electrode cell for the electrowinning of metal from dilute solutions. J Appl Electrochem 21(2):124-129

15. Salas-Morales JCE, Evans JW, Newman OM, Adcock PA (1997) Spouted bed electrowinning of zinc. I. Laboratory-scale electrowinning experiments. Metall Mater Trans B 28B(1):59

16. Balcerzak M, Pergol K (2003) Selective determination of platinum and palladium in iodide media by derivative spectrophotometry. Chem Anal 48(1):87-95

17. Takeuchi S, ShanWang X, Rhodes MJ (2005) Discrete element study of particle circulation in a 3-D spouted bed. Chem Eng Sci 60:1267-1276 
18. Dweik BM, Liu CC, Savinell RF (1996) Hydrodynamic modelling of the liquid-solid behaviour of the circulating particulate bed electrode. J Appl Electrochem 26(11):1093-1102

19. Scott K (1988) A consideration of circulating bed electrodes for the recovery of metal from dilute solutions. J Appl Electrochem 18(4):504-510

20. Szafran RG, Kmiec A (2004) CFD modeling of heat and mass transfer in a spouted bed dryer. Ind Eng Chem Res 43(4): 1113-1124

21. Du W, Bao X, Xu J, Wei W (2006) Computational fluid dynamics (CFD) modeling of spouted bed: assessment of drag coefficient correlations. Chem Eng Sci 61(5):1401-1420

22. Logothetis N (1989) Quality through design: experimental design, off-line quality control and Taguchi's contributions. Clarendon, Oxford

23. Trainham JA, Newman J (1977) A flow-through porous electrode model: application to metal-ion removal from dilute streams. J Electrochem Soc 124(10):1528-1540

24. Meredith RE, Tobias CW (1962) onduction in heterogeneous systems. In: Delahay P, Tobias CW (eds) Advances in electrochemistry and electrochemical Engineering, vol 2. Wiley, New York, p 15
25. Lacin O, Sarac H (2005) Measurements of mass transfer rates in a rectangular liquid fluidised bed using LCDT. Powder Technol 152(1-3):9-15

26. Yasin HM, Denuault G, Pletcher D (2009) Studies of the electrodeposition of platinum metal from a hexachloroplatinic acid bath. J Electroanal Chem 633(2):327-332

27. Dané LM, Janssen LJJ, Hoogland JG (1968) The iodine/iodide redox couple at a platinum electrode. Electrochim Acta 13(3):507-518

28. Swathirajan S, Bruckenstein S (1983) The anodic behavior of iodide at platinum in the presence of an iodine film under potentiostatic steady-state and hydrodynamic modulation conditions. J Electroanal Chem 143(1-2):167-178

29. Akkermans RP, Fulian Q, Roberts SL, Suárez MF et al (1999) Laser-activated voltammetry. mechanism of aqueous iodide oxidation at platinum electrodes: theory and experiment. J Phys Chem B 103(39):8319-8327

30. Bard AJ, Stratmann M (eds) (1985) Encyclopaedia of electrochemistry. Wiley, Weinheim

31. Weast RC (ed) (1988) CRC handbook of chemistry and physics. CRC Press, Boca Raton 